problemas externos, a la Madre Juana le quedó la tarea de ocuparse por cuenta propia de la cuestión de la autoridad, y lo que hizo fue incorporarla al texto de sus sermones. Resulta entonces que la propia experiencia mística es lo que le confiere autoridad para predicar. Es Cristo quien ha querido hablar a través de ella para lograr la salvación de los hombres y para completar su revelación. Así, pues, la experiencia mística le permitió a la Madre Juana hacer a la vez el papel lícitamente femenino de visionaria y el papel canónicamente masculino de predicador, de autor de sermones ${ }^{22}$. Pese a su falta de rango sacerdotal y de saber formal, pudo ejercer una función pastoral negada en principio a la mujer.

RONALD E. SURTZ

Brinceton Uxiversity

\title{
GILMAN SOBRE GALDÓS UNA APROXIMACIÓN A SU LIBRO MÁS RECIENTE
}

Con la publicación de Galdós and the art of the European novel: 1867-18871, Stephen Gilman corona largos años de labor crítica en torno al novelista canario. El libro - aportación seminal a los estudios galdosianos - recoge, considerablemente ampliados y ordenados de manera coherente para articular una hipótesis novedosa, trabajos publicados en Anales Galdosianos (1966, 1970, 197ó, 1978), la Nueva Revisia de Filologia Hispánica (1949, 1961, 1975), la Revista Hispánica Moderna (1968), Estudios literarios de hispanistas norteamericanos dedicados a Helmut Halzfeld (1974) y Les culiures ibériques en devenir: Essais publés en hommage à la mémoire de Marcel Bataillon (1979).

Desde el momento en que Dorio de Gádex lo marcó con el epíteto de "don Benito el garbancero" en Luces de Bohemia, la suerte de Galdós ante la crítica ha sufrido altibajos singulares. Acusado de "vulgar" y de "carecer de estilo" (como en su momento Dostoievski e incluso Joyce) por sus coetáneos ValleInclán y Unamuno -entre los generacionistas del 98 es excepción el fervor entusiasta de Azorín - fue ignorado por la oficialidad literaria del régimen franquista, que no le perdonó ni su secular liberalismo ni las manifestaciones de adhesión socialista de los últimos años. A la crítica norteamericana -en la que Gilman ocupa el puesto más destacado- debemos la reivindicación

22 De hecho, aunque las revelaciones de la Madre Juana se presentan como "sermones", carecen totalmente de la estructura típica del sermón medieval, con su técnica homilética de divisiones y subdivisiones. En los sermones de la Madre Juana no hay prácticamente nada de exégesis escrituraria; lo que hay en su lugar son alegorías triviales. Lo grueso de ellos consiste en una amplificación novelada de los relatos evangélicos, seguida de la descripción (con glosas) de las fiestas alegóricas celebradas en el cielo. Aunque inspiradas en el relato evangélico, esas descripciones no pueden considerarse explicación del texto sagrado.

1 Princeton University Press, Princeton, 1981. 
espectacular del novelista, iniciada a partir de la década del 40, y que produce la revista Anales Galdosianos de Austin, Texas. Con este precedente, a más del relajamiento de la censura, la explosión editorial y las adaptaciones cinematográficas de Buñuel, Galdós vuelve al favor de la crítica de su país.

Descontando los estudios de conjunto sobre su vida ${ }^{2}$ y su obra ${ }^{3}$, la bibliografía crítica galdosiana ${ }^{4}$ ha tomado, como señala Roger L. Utt ${ }^{5}$, tres direcciones que aún persisten desde su auge inicial en la década del 50: el estudio de los personajes (en especial Fortunata y Maxi), el análisis de la estructura general, y la exposición del significado socio-político-filosófico - y aun psicológico- de las novelas. En la primera dirección, y tomando como foco de estudio a Fortunata y Jacinta, la obra magna de Galdós - a la que Gilman dedica mayormente su libro y cuyo manuscriło compró en Madrid a nombre de Harvard para la Houghton Library, donde aparece catalogado como Ms. Span 93-, destacan las aportaciones de Lucille Braun, Stephen Gilman y Joan Connelly Uliman y George Allison ${ }^{6}$. En la segunda, Ricardo Gullón, Agnes Moncy Gullón y Phyllis Zatlin Boring ${ }^{7}$; y en la tercera, Carlos Blanco Aguinaga, Julio Rodríguez Puértolas, Joseph Schraibman y, de nuevo, el citado trabajo de Ullman y Allison ${ }^{8}$. Sólo recientemente - y Gilman ha abierto brecha en este sentido- ${ }^{9}$ se empieza a abordar el examen de los componentes de la novela, como los motivos simbólicos. En esta línea se sitúan los ensayos ya mencionados de Roger Utt y Agnes Money Gullón, ambos de 1974 y claramente influidos por el primero.

Un manual reciente ${ }^{10}$ describe las corrientes actuales dentro de los estu-

2 Chemente Cimarra, Galdós, Nova, Buenos Aires, 1947; H. C. Bhrkowitz, Benito Pérez Galdós, Spanish liberal crusader, Madison, WI, 1948; María Zambrano, La España de Galdos, Taurus, Madrid, 1960; Soledad Ortega, Cartas a Galdós, Rev. de Occidente, Madrid, 1964; Carmen Bravo Villasante, Gaidós visto por sí mismo, Magisterio Español, Madrid, 1970; Emilia Pardo BAZÁn, Cartas a Benito Pérez Galdós (1889-1890), ed. C. Bravo Villasante, Turner, Madrid, 1975.

${ }^{3}$ Joaquín Casalduero, Vida y obra de Galdós, Gredos, Madrid, 1951; Íns, 1952, núm. 82 ; Ángei del Río, Estudios galdosimos, Zaragoza, 1953; Federico Carlos SÁINZ UE Robless, "Don Benito Pérez Galdós. Su vida. Su obra. Su época", introducción a las Obras completas, Aguilar, Madrid, 1958; Ricardo Guliôn, Galdós, novelista moderno. Taurus, Madrid, 1960

4 Véase Theodore A. Sackett, Pérez Galdós: An annotated bibliography, Univ, of New Mexico Press, Albuquerque, 1968; J. E. VAREY, "Galdós in the light of recent criticism", GS, 1-35; Hensley C. Woodbridge, Benito Pérez Galdós. A selective annotated bibliography, The Scarecrow Press, Metuchen, NJ, 1975.

${ }^{5}$ R. L. UTT, “ "El pájaro voló»: observaciones sobre un leitmotif en Fortunata y Jacinta", $A G$, 9 (1974), 37-50.

6 L. BRAUn, "Galdós' recreation of Ernestina Manuel de Villena as Guillermina Pacheco", $H R, 38$ (1970), 32-55; "The novelistic function of Mauricia La Dura in Galdós' Fortunata y Jacinta", Symposium, Winter 1977, pp. 277-289; S. Gilman, "The consciousness of Fortunata", $A G, 5$ (1970), 55-66; y J. C. Ullman y G. Allison, "Galdós as psychiatrist in Fortunata y Jacinta", $A G$, $9(1974), 7-36$

7 R. Gullón, "Estructura y diseño en Fortunata y Jacinta", en Técnicas de Galdós, Taurus, Madrid, 1970, pp. 135-220; A. M. GULLÓN, "The bird motif and the introductory motif: Structure in Fortunata y Jacinta", $A G, 9$ (1974), 51-75; y P. Z. BORING, "The streets of Madrid as a structuring device in Fortunata y Jacinta", $A G, 13$ (1978), 13-22.

8 C. Blanco AGUinaGa, "On the birth of Fortunata", $A G, 3$ (1968), 13-24; "Entrar por el aro: restauración del 'orden' y educación de Fortunata”, en La historia y el texto literario: tres novelas de Galdós, Nuestra Cultura, Madrid, 1978, pp. 49-94; J. RODRíguez PuÉR TOlas, Galdós: burguesia y revolución, Turner, Madrid, 1975; J. ScFRAIBMAN, Dreams in the novels of Galdós, Hispanic Institute in the United States, New York, 1960; Ullman y Ali.ison, art. cit., n. 6.

9 "The birth of Fortunata", $A G, 1$ (1966), 71-83.

10 Intraduction to scolarship in modern languages and literatures, ed. Joseph Gibaldi, Modern Language Association, New York, 1981. 
dios literarios, a saber: estudios lingüísticos, edición de textos, estudios históricos, crítica y teoría literarias. Dicho de otra manera, la aproximación de la palabra, la fijación del texto, la reconstrucción del contexto y la interpretación de la obra, en su doble vertiente de teoría y praxis. Dentro de aquélla, hay cuatro enfoques posibles: el genético, que estudia la creación e intención de la obra, y pone el énfasis en el autor; el pragmático, que estudia el impacto de la obra y pone el énfasis en el lector; el semiótico, que estudia el lenguaje de la obra en sus dos ejes de paradigma y sintagma y pone el énfasis en el texto mismo; y el mitográfico, que estudia la información que contiene éste, atendiendo a la relación entre obra y mundo. Cabe puntualizar que existe un movimiento dialéctico entre estos esfuerzos y que a veces resulta difícil precisar fronteras entre uno y otro. Desde este esquema, podríamos decir que Galdós and the art of the European novel combina dos enfoques: el contextual (los estudios histótios) y el textual (la rritica literaria propianente dicha).

El enfoque histórico - sin duda el más frecuentado por los estudios literarios- incluye la biografía, la búsqueda de fuentes e influencias, la descripción de los contextos (ideológico, social y cultural), la historia de formas y géneros y la historia literaria como tal. En el caso de Gilman, la atención se centra, más que nada, en la consideración del género novelístico en el diecinueve desde la obra galdosiana en concreto. Lo que a partir de Bajtín llamamos la "poética histórica", que concibe el texto como lugar de encuentro entre dos caminos: la escritura es lectura del corpus literario anterior; el texto, absorción de y réplica a otros textos. Amplía las nociones de intertertualidad y dialogismo ${ }^{11}$ para reconstruir

the experiential context of Fortunata. By this I mean, specifically, first, Galdós' earlier novels, which he expected his readers to have read; second, novels by other novelists (primarily Cervantes, Dickens, Balzac, Zola and Clarín), which Galdós had read and which he expected his best readers to have read; and third, other novels, which Galdos either could not have read or had not read as far as we know (Ulysses, Huck Finn, La thartreuse de Parme, War and Psace, The Idiot), but which inevitably accompany us as read.

La aproximación crítica a Fortunata y Jacinta se da aquí desde una perspectiva semiótica, ya que Gilman estudia el lenguaje de la obra: cómo está montado el texto para formar una estructura significativa unitaria, coherente. La atención recae, no sobre el nivel del discurso, sino sobre el de la historia ${ }^{12}$ : interesan las asociaciones simbólicas de personajes (actantes) y sus acciones (funciones). Sin embargo Gilman rechaza la jerga estructuralista ("I refuse on principle to talk about narremes") y el culto al texto todopoderoso, aislado de la experiencia humana. Saludablemente lejos de toda ortodoxia teórica, aprovecha el legado de la crítica novelística del siglo xx: Georges Lukács (Teoría de la novela, 1920), Albert Thibaudet (Réflexions sur le roman, 1921), Percy Lubbock (The craft of fiction, 1926), Américo Castro (introducción a la edición de Porrúa del Quijote, 1960), y Northrop Frye (Myth and symbol, 1963). Aunque cabe admitir que echamos de menos referencias concretas a Kristeva y Bajtín, cuyas ideas

11 Julia Kristeva, Le texte du roman, Mouton, La Haye, 1970; y Mikhail Bakhtinse, La poétique de Dostoïevski, Éds. du Seuil, 1970 (Iª ed. rusa, 1929).

12 Empleamos los términos de T. Tonorov, "Las categorías del relato literario", en Análisis estructural del relato, Tiempo Ciontemporáneo, Buenos Aires, 1974, pp. 155-192. 
maneja, así como al texto de Ortega y Gasset que anticipa el meollo de la tesis lukacsiana: Meditaciones del Quijote (1914), con su continuación Ideas sobre la novela (1924-1925).

Galdos and the art of the European novel: 1867-1887 se divide en tres partes: 1. The historical novelist (capítulo I, "Galdós: 'Life and times' "'; capítulo II, "La Fontana de Oro"; capítulo III, "From Trafalgar to Doña Perfecta"; capítulo IV, "La desheredada"). II. Fortunata y Jacinta in prospect (capítulo V, "From La desheredada to Lo prohibido"; capítulo VI, "A colloquium of novelists"; capítulo VII, "The novelist as reader"). III. Fortunata y Jacinta (capítulo VIII, "The challenge of historical time"; capítulo IX, "The art of listening"; capítulo X, "The art of genesis"; capítulo XI, "The art of consciousness"; capítulo XII, "Retrospect") y un apéndice, "Classical references in Doña Perfecta". El libro entero está pensado desde y para Fortunata y Jacinta: la primera parte describe tos inicios galdosianos como antecedente de la novela la segunda presenta a Forlunata como proyecto, examinando su contexto literario inmediato y la tercera, verdadero meollo de este trabajo, la estudia como realidad cumplida, ihuminando la riqueza de una novela tan fecunda en posibilidades interpretativas.

Desde la Revolución Francesa, la historicidad ha dominado el pensamiento europeo. En The historical novelist Gilman aborda el problema de la historia como punto de arranque del novelar galdosiano. Aquí la influencia del krausismo es notable: según éste, la sociedad del siglo XIX estaba enferma y podía elegir curarse; entonces la literatura se concibe como medio de regeneración. La primera novela de Galdós - La Fontana de Oro, 1868- contiene los balbuceos de su don profético: el fracaso del trienio liberal de 1820-1823 se recrea para augurar la derrota de la revolución liberal del '68, la "Gloriosa". De igual manera, las cuatro series de Episodios nacionales (la primera comienza en $1873 \mathrm{con}$ Trafalgar) articulan la propuesta de una lección moral para España.

Con la aportación de la historicidad (aprendida de Balzac, del que se "desayunó" en 1867, según confiesa en sus Memorias), Galdós propone para la novela española el antídoto a los cuadros de costumbres convertidos en materia novelesca por Fernán Caballero en su best-seller de 1849, La gaviota. Contra la arcadia tradicional de una ruralía petrificada en el tiempo, la conciencia histórica en un mundo urbano. Las tres influencias que convergen en el primer experimento de Galdós - la novela histórica, la literatura costumbrista y el periodismo- explican en cierta medida su fracaso parcial: énfasis en la peripecia, simplificación caricaturesca de los personajes y el paternalismo de un narrador "reportero". La respuesta inicial del autor al dilema de atender a la vez los niveles diacrónico y sincrónico del problema de España consistió en bifurcar su empresa narrativa: por un lado la historia pasada (los Episodios nacionales), por el otro la sociedad presente (las "novelas españolas contemporáneas", que comienzan en 1876 con Doña Perfecta).

Gilman insiste en que hay que ver a esta última desde la perspectiva de Américo Castro ${ }^{13}$ : el conflicto aquí es social, entre los roles heredados y la historia en marcha. Se trata de una transformación del problema intercastizo, en la que liberales y afrancesados son los nuevos "conversos" perseguidos por la oficialidad católica. Galdós percibió con lucidez que en España la pugna entre lo antiguo y lo nuevo se ha planteado secularmente en términos religiosos. 
Si historia (movimiento) e individuo (sentido) se deslindaron en los albores de la obra galdosiana, con La desheredada (1881) tenemos su primer intento de fundir historia y biografía. La lección de Balzac, aplicar las técnicas de la novela histórica a la sociedad contemporánea, ha sido plenamente asumida. Experimento inicial con la herencia naturalista de Zola, supone la creación de la novela urbana en términos españoles, documentando el medio social de la lengua oral; explora la conciencia en su flujo temporal a través del dialogue indirecte libre que Flaubert prestigió; y eleva una vida clínicamente documentada a la estatura del mito. Del mismo modo en que Emma Bovary y Nana representan a Francia, la Isidora de La desheredada es la España corrupta y entregada al lujo consumista de las vísperas de la Primera República. Paradójicamente, Cervantes aflora en este texto naturalista, jugando irónicamente con las expectativas del lector desde un título que despista y nos mueve a identificamos con una vida enajenada.

Pero La desheredada adolece de una falla seria: la ausencia de libertad de la protagonista para reaccionar y crecer. No será hasta Fortunata cuando encontremos el primer personaje cervantinamente autónomo de Galdós. En El amigo Manso (1882), cuyo protagonista se nos presenta diciendo "Yo no existo", el autor comienza a socavar las pretensiones documentales del naturalismo y recobra el factor lúdico del novelar. La autonomía de Máximo corta la dependencia del individuo de la tiranía de herencia y ambiente.

En Fortunata y Jacinta in prospect, Gilman examina la novela galdosiana como género polifónico en el que el dialogismo asume dos direcciones: la de la réplica a sus novelas anteriores, así como la de la réplica a las obras de sus coetáneos del realismo y el naturalismo decimonónicos - Clarín, Flaubert, Balzac y Zola - y en última instancia, al creador de la novela moderna, Cervantes. En la consideración de este último punto hay que advertir que es una lástima que Gilman no comentara - siquiera brevemente- el diálogo novelístico (paralelo al epistolar, amoroso) entre la Pardc Bazán y don Benito, reconocido por primera vez por Carmen Bravo Villasante en el caso de Memorias de un solterón (1891) y Tristana (1892), y que hoy estudia Francisca González Arias, discípula suya, para su tesis doctoral en Harvard.

Antes de emprender en Fortunata y Jacinta la antítesis al naturalismo de La desheredada (el dilema esencial propuesto por la biografía de Isidora es el de la posibilidad de la libertad en un siglo obsedido por la historia), y después de un tanteo irónico en El amigo Manso, Galdós agota sus posibilidades en El doctor Centeno, Tormento, La de Bringas y Lo prohibido. La dimensión mítica de estas novelas en que proliferan las mentes enfermas hace encarnar la corrupción del cuerpo político español en mujeres: Isidora, la Regenta, Rosalía; en el caso de esta última, su prostitución final señala a la del régimen de Isabel II. Es refrescante entonces la admisión de culpa del narrador-personaje masculino al terminar La de Bringas, que confiesa haber sido su cliente. Con ello el lector se contamina de la culpa del desastre español. La ampliación de esta confesión masculina se da en Lo prohibido, novela poco lograda. Gilman observa atinadamente que en la obı a de Galdós los personajes masculinos sólo se representan a sí mismos, mientras que los femeninos - superiorísimos - tienen densidad simbólica. En este lugar habría sido interesante una reflexión sobre la dialéctica de sexismo/feminismo en la narrativa galdosiana. Para comenzar, y es un pecado compartido por Flaubert, Zola y Clarín, el hecho de utilizar a la mujer para simbolizar el deterioro de sociedades regidas por hombres. Por otro lado, 
Galdós, quien como es notorio, es un novelista de grandes personajes femeninos, a menudo los trata con cierta ambigüedad paternalista. El caso es patente en Tristana, la novela que articula de manera más explícita el feminismo del autor, y que paradójicamente -y para disgusto de su colega y compañera de aventuras eróticas, doña Emilia Pardo Bazán- se queda trunco con la mutilación física de la protagonista: toda la novela está montada ¿irónicamente? sobre el nefasto refrán hispánico "la mujer casada/la pierna quebrada y en casa". Aun la liberación de la misma Fortunata, cuyo triunfo espiritual es innegable, se da en términos patéticos: sólo como madre, el rol asignado desde siempre por la sociedad patriarcal a su sexo.

La novedad de Fortunata y Jacinta no se explica sólo en términos de la insatisfacción de Galdós con su trabajo anterior (Fortunata será la antítesis de Isidora y la elaboración plena de Camila, aquel personaje menor pero saludable

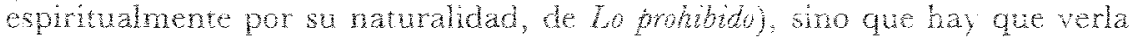
como una recuperación de Cervantes a partir de las reflexiones del autor sobre las obras de Clarín, Flaubert, Balzac y Zola. Galdós celebró mucho La Regenta, que apareció en 1885. Maxi y Ana Ozores comparten - como Emma- la locura de la lectura. Madame Bozary es toda una lección de cómo emplear cl modelo cervantino en el diecinueve, haciéndolo trascender la mera sátira social y política y la elaboración del mito de la decadencia española. El meolio está en la creación de caracteres "incitados", "casos máximos de vida" (los términos son de Castro: "incitación" = "incorporación consciente de la excitación o el entusiasmo"): Ana, Maxi, Emma, Fortunata. No se trata de caracteres que sufran o vivan intensamente nada más, sino que asuman hasta sus últimas consecuencias la "locura heroica" (curiosamente en este punto Gilman no alude a la noción lukacsiana de "héroe problemático", imprescindible). El diálogo de los novelistas decimonónicos con Cervantes se da, pues, en este orden: Flaubert>Clarín > Galdós. En Fortuná́a y Jacinta Maxi resultará una caricatura naturalista del don Quijote derrotado y ridículo de la primera parte; Fortunata, con su autonomía innata, se acerca al don Quijote de la segunda: el que, ennoblecido, emprende el regreso y muere en su casa con dignidad.

El dialogismo intertextual que convierte a la novela en género polifónico ha sido, desde el Quijote, inherente a la expresión más sofisticada de esta forma literaria: el novelista nos entrena para mirarlo mirarse trabajar. Ahora bien, la herencia cervantina en Galdós produce resultados muy distantes del juego borgiano, más cercano al ajedrez literario que a la creación de vidas humanas en el tiempo. Si Cervantes establece la ecuación entre lectura y conciencia (lectura: las nuestras, las del personaje y las del autor, tácitamente presentes en nuestra descodificación actual del texto), el propósito es sumergirnos en la experiencia del ente de ficción para convertirnos - al decir de Proust- en mejores lectores de nosotros mismos.

Hasta aquí Gilman ha considerado los factores de historia y literatura como contexto que posibilita el milagro artístico de la novela que da título a la tercera parte de su libro: Fortunata y Jacinta. Como entramos aquí al centro fundamental del texto, a la vez el más fecundo y polémico, vale la pena examinar con detenimiento - capítulo a capítulo- la propuesta de su autor.

"The challenge of historical time" repone el tema que abrió el libro. La crítica marxista se ha ocupado por razones obvias del auge de la novela en el diecinueve, también manifestación del historicismo del siglo. Ello es posi- 
tivo en la medida en que su enfoque plantea implícitamente un problema esencial: $\dot{c}$ cómo lograron estos novelistas transformar la materia prima socio-histórica en obras de arte duraderas? Pero Gilman entiende que esa crítica ofrece una interpretación equivocada de Fortunata y Jacinta: la ve como la historia de una víctima proletaria presa en el engranaje de una sociedad burguesa que pide a gritos la revolución. La novela es válida artísticamente por ser "realista" en términos sociales. Que esto es incorrecto lo revela la obra misma, con su final contrarrevolucionario.

La novela moderna nace con la interrupción del episodio entre don Quijote y el vizcaíno en el capítulo 8 del libro de Cervantes. La narración se hace consciente de sí misma a través de la interrupción irónica (forma efectiva de lo que hoy llamamos la autorreferencialidad): nos damos cuenta de que el tiempo de la acción y el de la escritura no coinciden. La estratagema del manuscrito encontrado - prueba documental de la "verdad" de la ficción, pasado que permite a lo narrado funcionar como presente- se subvierte paródicamente y asistimos al proceso de creación. El logro máximo de la interrupción es la ilusión de libertad para los personajes: libertad del dominio del creador, y libertad del sometimiento forzoso a la secuencia cronológica de los episodios. (Aquí cabría apuntar, aunque Gilman no lo consigna, que José Antonio Maravall esiudia el recurso bajo el nombre de "la técnica de la suspensión"14, proponiendo otra interpretación. Según ésta, la suspensión — traslación a la literatura del arcana imperii de Tácito que se pone de moda como estrategia de poder en la monarquía absoluta del XVII- es una técnica para manipular a los lectores y glorificar la libertad absoluta del narrador.) Para Augusto Centeno, maestro de Gilman, lo que Cervantes consiguió con ello fue convertir la materia de la novela de caballería (la aventura) en la materia de la novela moderna (la experiencia), o dicho en palabras de Castro: desde el Quijote la novela no narra cl acontecer, sino que presenta a los personajes sintiendo y viviendo ese acontecer. El segundo logro de la interrupción está en entrenar al lector en la percepción de la ficción. Como lectores del Quijote compartimos con el protagonista el despertar a la realidad a medida que avanza la rarración. Nos liberamos con él de la ficción. Y ello se hace extensivo -esta conciencia de la ficcionalidad - a las ficciones que sociedad y cultura nos imponen. La novela moderna nos ayuda a descubrir cómo liberarnos. Fortunata y Jacinta recupera esta lección cervantina. En ella la estratagema documental de la novela de caballería (el manuscrito encontrado) es sustituida por la estratagema histórica: la recreación detallada del mundo político, social y económico del Madrid de fin de siglo. De esta nueva "ficción" habrá de librarse Fortunata.

Fortunata y Jacinta sigue el patrón típico de la novela del diecinueve: se abre con una larga introducción que reconstruye el medio. Más aún: la excede; esta introducción supera en densidad y extensión a la de las novelas coetáneas, con la excepción de Moby Dick y quizás Nostromo. Curiosamente, ya Zola había aban. donado la técnica, y Galdós también. Sin embargo Fortunata vuelve a reincidir en los panoramas de las primeras series de Episodios, a los que ya había renunciado el autor en su etapa naturalista. Más curioso todavía es el hecho de que muchos de los detalles que da en esta introducción son prescindibles para el desarrollo de la historia. ¿PPor qué entonces el esfuerzo de reconstruir el Madrid decimonónico de los Arnaiz y los Santa Cruz? La frase inicial, "Las noticias 
más remotas que tengo de la persona que lleva este nombre |Juanito Santa Cruz]. . .", propone la clave irónica para leer todo el panorama histórico que sigue. Connota que el medio de don Baldomero y su clan es yá intrínsecamente pasado: la no importancia de tanta pompa hace que los eventos de la familia parezcan remotos. Al contar este Madrid, Galdós no está celebrando la historia como modo de explicar la vida novelísticamente, sino denigrándola como responsable de la desvalorización de tanta vida humana. Si Fortunata y Jacinta rebate las convenciones de la novela naturalista, también lo hace con las de la novela histórica, de la cual procede aquélla. Todo ello se reduce a algo esencial: según Cervantes subvirtió la novela de caballería de su época, Galdós subvierte la estructura convencional de la novela del siglo XIX.

Como protagonista, Fortunata es belleza física, pero sobre todo salud mental, autenticidad que ilumina cuanto toca. En el capítulo "Las Micaelas" ganamos acceso por primera vez a su conciencia. La prisión - - como los celos y d naufragio - es un recurso novelistico tradicional para intensificar la experiencia. Cuando las reclusas contemplan la construcción de la pared que les robará el paisaje, el horizonte, sabemos que la pared en ascenso simboliza la pérdida de la libertad: el dique artificial que contendrá el fluir natural del alma de Fortunata hasta que rompa en aquel "estallido de infinitas ansias" con que regresa a Juanito al final de la parte II. La trayectoria de Fortunata es ascendente, y con ella Galdós pretende mostrar que la salvación aún es posible. Lo que importa es cómo ella se forja a sí misma (como el don Quijote que dice "Yo sé quién soy, y sé que puedo ser no sólo los doce pares de Francia. . .") cuando "concentrándose en una sola idea, se determinaba con desusado vigor y fortaleza".

Volviendo al final de la novela, aunque el narrador - amigo de los Santa Cruz, y por lo tanto, burgués - flirtea de vez en cuando con la idea de la reconciliación de las clases sociales, el don del bebé de Fortunata no arreglarú nada: lógicamente podemos intuir que el niño no tendrá más remedio que convertirse en otro señorito, y quizás peor que Juan (en este caso tendrá tres madres --Barbarita, Guillermina y Jacinta- y un padre ausente). Marx y Freud nos obligan a otra lectura del final, no tan feliz. Blanco Aguinaga tiene razón cuando señala ${ }^{15}$ que la novela presenta la "sumisión absoluta" (palabras de Maxi al final) de la pequeña burguesía y el pueblo frente al poder establecido: la burguesía comercial y financiera. El saldo son tres muertos (Mauricio, Fortunata y Feijoo, el viejo liberal), un pequeño burgués loco, una futura maestrita y un modelo de pintores. Todo ello es cierto en términos sociales. Sin embargo, y a nivel tanto humano como novelesco, el regalo épico del niño - el tan mentado "rasgo", don de vida no correspondido que subraya la superioridad moral del dador - constituye una vigorosa afirmación de humanidad. Galdós no excusa ni pretende curar a la sociedad enferma que presenta en su novela, sino exaltar un ser que transitó su propio sendero, y al hacerlo reivindica la condición humana. Por eso incluso sentimos cariño y nostalgia por ese Madrid: la obra no nos deja la amargura que produce el medio de Emma Bovary. Como en el Quijote, hemos asistido a la salvación del espíritu en términos puramente humanos. Fortunata ha perdonado no sólo a Jacinta, sino a Madrid y a su historia.

"The art of listening" se inserta en la corriente más novedosa de la crítica

15 "Entrar por el aro. .." 
de Galdós, la que atiende al nivel del discurso en el relato; tradicionalmente, como hemos visto, los estudios galdosianos han examinado la historia (personajes, estructura y contenido ideológico). Tras la intuición lúcida de la Pardo Bazán en un ensayo de 1891, Joaquín Gimeno fue el primero en estudiar el "problema" del discurso narrativo de Galdós que volvió a buena parte de la crítica en contra suya: el empleo de los tópicos del intercambio oral en lugar de la creación de un estilo propio. Al combinar retóricas de diversas fuentes - oratoria política, sermones religiosos, la oficialidad burocrática, la prensaGaldós reconstruye y exagera irónicamente (como sus ilustres antecesores: Cervantes, el autor del Lazarillo, Rojas; en cuanto a este último, Gilman ha trabajado agudamente la oralidad en La Celesitina) un estado sociolingüístico de degeneración alarmante.

El lenguaje de los tópicos funciona en Fortunata y Jacinía de manera pare-

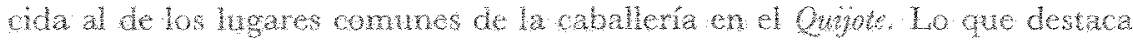
a Fortunata es precisamente su esfuerzo enome de crearse a sí misma con los elementos (lengua, valores) desgastados que su sociedad, representada por Jua. nito, le ofrece. Para Fortunata los valores no son meras palabras, y el lenguaje es un instrumento para decir verdades. Al principio de la obra casi no habla, como un animalito. Pero en su descubrimiento de "la idea blanca" en Las Micaelas demuestra un discurso mental articuladísimo; más aún en el de "la pícara idea" y cuando deja muda a Guillermina en el diálogo tenso que entreoye Jacinta. Ello implica que su anterior incapacidad lingüística era tan sólo aparente, un rechazo implícito de la trivialidad de los tópicos de la sociedad madrileña.

La técnica naturalista del diálogo indirecto cede ante el diálogo directo de tradición cervantina en esta novela que se centra en torno al lenguaje hablado. Para la caracterización interna, Galdós penetra la sensibilidad de Fortunata, dotándola de palabras y conceptos: manera de acercamiento entre narra* dor y personaje que contrasta con el distanciamiento irónico del diálogo indirecto libre.

Gilman no lo trata aquí, pero paralelo al dialogismo oral que articula el discurso del narrador en esta novela que carece de una presencia autorial decisiva, hay otro literario que estructura dialécticamente el habla de los personajes. En esta línea se sitúan los trabajos que Alicia Andreu tiene en preparación: "Diálogo de voces en Fortunata y Jacinta" y "Juanito Santa Cruz en diálogo con su propio mito", que habrán de reunirse con otros en su próximo libro La estructura dialógica en la narrativa de Galdós. Andreu propone que Fortunata y Jacinta muestra una textura multigenérica en que conviven varios textos - cosa que ya vio en relación con las novelas españolas de consumo en torno al arquetipo de la "Mujer virtuosa" en Galdós y la literatura popular (1982) en el caso de La desheredada y Tormento - y que la narración rompe con la habitual lógica unívoca del discurso realista. En Fortunata cada personaje lleva a cuestas un género literario con el cual se mantiene en constante estado de diálogo. Jacinta lleva sus novelas de folletín. Fortunata dialoga con un texto romántico cuyos orígenes se podrían remontar a novelas tales como Manon Lescaut y La dama de las camelias. Juanito Santa Cruz lleva su Don Juan de Tirso y de Zorrilla. Guillermina Pacheco, la "rata eclesiástica", dialoga con un texto religioso seudo-burgués que se propaga en la prensa católica del diecinueve y en el que se le predica al público femenino la necesidad de una actividad catequizante orientada a la caridad y al consuelo de las clases marginadas. Maximiliano 
Rubín pierde el juicio como resultado de la ávida lectura de libros de filosofía. $Y$ el texto del buenazo de Ido del Sagrario es una mezcla híbrida de la obra de Calderón de la Barca y la novela de folletín.

"The art of genesis" es una re-elaboración del trabajo más polémico de Gilman sobre la novela: "The birth of Fortunata", publicado en el primer número de los Anaies Caldosianos (1966). Es ante todo una reflexión sobre el texto a partir del estudio de su primer volumen. El nacimiento es el motivo estructurador de este "libro de génesis", según la muerte es el tema recurrente del último. Galdós liega a construir todo un árbol genealógico para buena parte de la ciudad como introducción a Juanito. Pero todo el panorama de la burguesía madrileña del primer volumen (el medio social de Jacinta y de Juanito) resulta una introducción irónica para Fortunata. La protagonista sale de la nada y el azar, como su nombre lo indica, y sin embargo se construye a sí misma: con todos sus privlegios heredados, el Delfin nunca llega a rey ni pierde el diminutivo por el cuai se le conoce. Juanito termina reconociendo "el vacío de la vida" y Fortunata diciendo "Soy ángel".

La situación emblemática de la novela (como en el Quijote la escena de los molinos de viento) es el primer encuen iro entre Fortunata y Juanito en la Cava, mientras ella come un huevo crudo. Se establece aquí tanto el mito de Fortunata como el simbolismo del ave que permea coherentemente la totalidad del texto. Veamos los elementos que de este último propone el episodio: Juan entra como animal de presa por la tienda de pollos de la tía de la protagonista, "pisando plumas y aplastando cascarones"; Fortunata - presa en la Cava, que asemeja "un castillo o prisión del Estado", cual las gallinas en sus jaulones- - se agasaja como tal, esponjándose en su mantón mientras come un huevo crudo. Ai llamado de la tía desaparece rodando escaleras abajo como si volara, y emite un "yiá voy" que resulta "digno canto de tal ave". Galdós no abandonará el simbolismo ornitológico - retórica naturalista que entronca con Zola y es compartida por Clarín - en el resto del libro. En la luna de miel jacinta y Juan comen pájaros fritos mientras la primera se apiada del bocado que tiene en la mano diciendo "Pobre ángel"; a Fortunata la rehabilitan en la sección de las filomenas ( = ruiseñores, eufemismo para las "pájaras malas") en el convento de Las Micaelas; doña Desdémona envía con Maxi a doña Lupe el mensaje críptico de que "la pájara mala sacó pollo esta mañana" para noticiar el nacimiento del verdadero Pituso; Fortunata "empolla" hasta que sale "como pajarito del cascarón" su "pícara idea"; duerme a su hijito "rezongando como la pájara en el nido"; Jacinta es la dulce paloma enrabiada que se enfrenta a Fortunata, la mala pájara enjaulada. . . La interpretación de Gilman ha tenido trascendencia crítica: la siguen, ampliando el argumento con nuevos ejemplos, Agnes Mloncy Gullón y Roger Utt, y la niega Carlos Blanco Aguinaga ${ }^{16}$.

Blanco Aguinaga entiende que es completamente equivocado el enfoque simbólico de Gilman, que interpreta la novela como el caminar de un personaje en un marco sociohistórico meramente accesorio. Aquí los puntos de su argumento: 1) Fortunata sí tiene linaje o antecedentes: el Cuarto Estado, implícito en la Cava de San Miguel como su lugar de origen. Aunque es huérfana -la connotación es de orfandad social- tiene parientes: Segunda y José Izquierdo. 2) La alusión al esponjarse como gallina en su mantón no se refiere 
a Fortunata como individuo sino como miembro de su clase, como madrileña del pueblo. 3) Las referencias de Gilman al lenguaje ornitológico son triviales: más que de motivos simbólicos se trata de tópicos lingüísticos del habla familiar. 4) El ave es punto de analogía no sólo para Fortunata, sino para otros personajes como Jacinta, doña Lupe. . . 5) Fortunata tiene una dimensión más erótica que angélica y 6) no es "escultura de sí misma", sino un personaje patético manipulado por los demás.

El trabajo de Blanco Aguinaga - fino e inteligente por demás-- es importante no en tanto que logra lo que se propone, rebatir la tesis de Gilman, sino en la medida en que nos anima a matizarla. La polémica replantea, a otro nivel, aquella que se produce entre Américo Castro (De la edad conflictiva) y José Antonio Maravall (La cultura del barroco), y que nos obliga a discernir la prioridad entre culrura y sociedad. En este caso, se trata del conflicto entre el sentido (GIman) y la historia (Aguinaga). Entendemos que una y otra de estas posturas pueden extremarse hasta hacerse reduccionistas, por lo que es saludable la confrontación mutua para corregir excesos. Es cierto que a Gilman se le puede criticar el desestimar el nivel documental del libro que tanto preocupa a Aguinaga - para éste la historia no es el contexto, sinø que funda el texto, y la relación entre los eventos políticos y la ficción se explicita en los títulos de la tercera parte: "La Restauración, vencedora", "La Revolución vencida", "Curso de filosofía práctica" y "Otra Restauración"-, pero de lo que no hay duda es de que ha entendido la novela en sus propios términos como nadie.

Retomemos críticamente el argumento de Blanco Aguinaga. En el primer punto, hay que reconocer que tiene razón: Fortunata sí tiene antecedentes que la limitan y explican en buena medida su situación desventajosa. Pero a nivel estructural, estos datos se escamotean inicialmente, creándose la ilusión novelesca de que sale de la nada. La ironía que marca el contraste entre antecedentes/resultado final de las vidas de Fortunata y de Juanito no puede pasar desapercibida. El punto 2 sería váiido si a) se diera seguimiento a la asociación simbólica entre el ave y las mujeres del pueblo, o b) no se le diera con respecto a Fortunata. Pero sabemos que sucede lo contrario. Cierto que a veces (punto 3) Gilman refuerza su planteamiento con ejemplos que poco aportan, por tratarse de frases lexicalizadas ("empollar" la "pícara idea"), lo que no quita que exista una retórica ornitológica coherente en el texto (como señalamos, Utt y Moncy Gullón han contribuido a precisarla), cosa que sin querer sugiere el mismo Aguinaga en el punto 4. El punto 5 alude a la interpretación de Gilman sobre el mito de Fortunata. Volviendo a la situación emblemática de la novela, Gilman propone que el pasaje recuerda el nacimiento de Eros de un huevo en el caos de la noche, según el mito que refiere Aristófanes en Los pájaros. Fortunata no aparece precedida por su genealogía, sale del azar y de la oscuridad de la Cava y la encontramos comiendo un huevo; además, es hermosísima. Interesantemente, después de presentar esta posibilidad interpretativa tan fecunda, Gilman nos dice que en realidad Fortunata no es Eros: el mito de origen es en el fondo un mito de metamorfosis, en que la Pitusa se convertirá en un ser alado. Nacida de un huevo en el cautiverio, al final volará al cielo después de decir "Soy ángel". Blanco Aguinaga señala un punto importante al subrayar el erotismo de la escena. Como todo gran personaje moderno, Fortunata es ambigua: es Eros (las connotaciones sexuales del acto de comer las babas del huevo crudo son clarísimas; por otra parte la pasión erótica -ob- 
sesiva, piénsese en el sueño de los tubos- es su norte en la vida), es madre (el huevo también es símbolo de fecundidad, y en ella estará su victoria final), y es ángel: honradez (el "rasgo" del don del niño la limpia de culpa, igualándola a Jacinta), libertad y afirmación de humanidad (fiel a sí misma, rompe barreras sociales para cumplir con su propia conciencia). En cuanto al punto final (6), Fortunata es escultura de sí misma tras haber sido manipulada por los demás: ni lo uno ni lo otro en términos absolutos. El final de la novela es tan ambiguo como el personaje: la victoria de Fortunata sólo puede darse desde su rol de madre, el único que le reconoce su sociedad y el único que dignifica a la mala mujer en la tradición cristiana occidental desde Eva (la carencia de Jacinta es precisamente la infertilidad). Una mujer soltera, trabajadora y autosuficiente como Aurora, sin hijos, queda necesariamente como "la mala", "la otra". Todo ello tiene ribetes patéticos. Pero al héroe probl" mático no lo podemos juzgax desde nuestros propios esquenas, $y$ desde los suyos, la liberación fmal de Fortunata es ciertamente un triunfo. Li don del hijo y la afirmación "Soy ángel" le dan piena estatura heroica, como lo entiende Bajtín:

Cé ne sont pas [.. .] les traits de la réalité, celle du personnage lui-même et de son environnement quotidien qui servent d'éléments constitutifs pour l'élaboration de son portrait, mais la signification de ces traits pour le héros lui-même, pour sa conscience de soi $[\ldots]$.

Il y a toujours dans l'homme quelque chose que lui seul peut découvrir à travers l'acte libre du mot et de la prise de conscience de soi, quelque chose qui n'admet pas de définition extérieure "par contumace"17.

En "The art of consciousness", y de nuevo a partir de Fortunata, Gilman examina cómo la novela absorbe la herencia cervantina. Como Zola, Galdós prefiere presentar a describir sus personajes. Pero en el caso de Fortunata ello se acentúa: casi no la vemos físicamente, desde la lacónica presentación del narrador: "Juanito vio algo que de pronto le impresionó: una mujer bonita, joven, alta. . " Lo que importa es la impresión que causa en los demás. Fortunata, que casi no aparece en el primer volumen, es su presencia constante, y el tema obsesivo de la luna de miel de Juanito y Jacinta. Su ausencia física no impide que se constituya en la realidad real del primer tomo. Aquí tenemos la ofensiva galdosiana - homenaje a Cervantes- contra Zola y el naturalismo: el regreso a la celebración de la conciencia. Una figura de la mente importa más que el Madrid mercantil cuya densa descripción nos pesa al inicio de la novela, y su conciencia logrará exorcizarlo al final. Fortunata es una heroína en lucha contra la sociedad, y sus armas son la verdad y la experiencia. A Galdós no le interesa tanto su ideal utópico de una sociedad natural regida por la "pícara idea" donde el amor se justifique a sí mismo ("querer a quien se quiere no puede ser cosa mala") y en que la maternidad sea el único sacramento ("esposa que no tiene hijos no es tal esposa"), sino el compromiso consciente que Fortunata asume con respecto al mismo.

El tema de Fortunata y Jacinta es entonces el tema de toda gran novela desde el Quijote: la creación del sentido del sin sentido, o como Lukács nos ha enseñado, una búsqueda de valores que en su aparente fracaso logra sin embargo triunfar.

17 Op. cit., pp. 83 y 96. 
La estructura de la novela se ha descrito de varias formas: como triángulos amorosos encadenados o conflicto de clases. También, aunque Gilman no lo menciona, como el mapa de Madrid en movimiento, o incluso - como lo percibe Lucille Braun $-{ }^{18}$ en términos proppianos o cuasi míticos, sintetizada en el sueño de Mauricia la Dura: una mujer de condición elevada (la Virgen, Jacinta) sufre por la pérdida del hijo (en la hostia, por la esterilidad). Entonces una mujer humilde (Mauricia, Fortunata), por medios poco ortodoxos (robo sacrílego del sagrario, parto y regalo del niño ilegítimo), le devuelve el hijo a la madre. Gilman entiende que es más pertinente verla a la manera cervantina, como una confrontación entre lo interno y lo externo, ya que la preocupación de Galdós fue moral: un intento de castigar a la España de la Restauración con una lección existencial.

Como el Quijote, Fortunata y Jacinta logra la síntesis de los personajes titulares, aparentemente antitericos. Fortunata es madre pero no es honrada: Jacinta es honrada pero estéril: al final Fortunata se hace ángel y Jacinta madre, y ambas se reconcilian liberándose de Juanito. En esta sección dedicada a examinâr el aspecto dialéctico de la herencia cervantina, falta una breve consideración de la ambigüedad sobre la que se erige la novela moderna. Desde el Quijote este elemento funda lo que Carlos Fuentes llama la "épica vacilante". La crítica ha acuñado distintos nombres para aludir al mismo fenómeno: perspectivismo, libertad, equívoco, integralismo, realidad oscilante. . Todo ello depende del famoso héroe problemático de Lukács. Para Kristeva la condición de modernidad de la novela radica en el hecho de que la disyunción entre los opuestos se presenta más como un doble que como dos irreductibles. En la primera novela moderna el caso está patente en la quijotización de Sancho y en la sanchificación de don Quijote. Y en Fortunata y. Jacinta tenemos - como señala Gilman - el mismo proceso de ósmosis que reconcilia a las protagonistas, con un eco claro en los personajes de Guillermina Pacheco y Mauricia la Dura, fundidos en la conciencia de Fortunata ${ }^{19}$.

El capítulo, que aborda la recuperación de la conciencia en esta novela decimonónica, no podía pasar por alto el problema del subconsciente, y termina con una rápida alusión a las intuiciones prefreudianas de Galdós — ciertamente insólitas, en especial en lo que al simbolismo onírico se refiere--, y que han sido estudiadas por Schraibman, Ullman y Allison, y recientemente, Braun.

Y llegamos al final. Pese a fallas menores - en el manejo de las citas de Fortunata y Jacinta no se sigue criterio fijo en cuanto al idioma: aunque casi todas éstas se dan en inglés, algunas se mantienen en el original (la concesión no se justificaría en un texto destinado exclusivamente a un público hispanista, pero el empeño de Gilman es dar a conocer a Galdós al lector americano); además, las referencias a la procedencia de las citas son insuficientes (sólo se da la página de las Obras completas de Aguilar, 1950-1951, cuando hacen falta los datos de volumen y capítulo); otras fallas son de carácter estructural: el libro se resiente de repeticiones y por momentos resulta un tanto desarticulado, aun cuando la tesis que propone se fundamenta de manera impecable-, visto en su conjunto Galdós and the art of the European novel: 1867-1887 constituye el primer paso importante en una empresa urgente para los estudios hispánicos: rescatar a Galdós como clásico de la gran novela occidental. Aportación

18 :The novelistic function of Mauricia la Dura. . ."

19 Ibid. 
imprescindible a la crítica galdosiana, el libro ilumina la obra del novelista canario considerada in toto a partir del examen fervoroso de su novela máxima, Fortunata y Jacinta. En el último capítulo, "Retrospect", Gilman nos da la clave que le permite hacer una lectura irónica de la novela (quizás su mayor acierto), y subvertir al dios del diecinueve, la Historia. Se trata - con la presentación del Madrid contemporáneo, prosaico y familiar a sus lectores- de la autopresentación de un narrador aburrido que se burla de su propio relato; otra vez Cervantes. 